\title{
Preparation of amino-Fe(III) functionalized mesoporous silica for synergistic adsorption of tetracycline and copper
}

\author{
Ziyang Zhang ${ }^{\mathrm{a}, \mathrm{b}}$, Huijuan Liu ${ }^{\mathrm{a}, *}$, Liyuan $\mathrm{Wu}^{\mathrm{a}}$, Huachun Lan ${ }^{\mathrm{a}}$, Jiuhui $\mathrm{Qu}^{\mathrm{a}}$ \\ ${ }^{a}$ Key Laboratory of Drinking Water Science and Technology, Research Center for Eco-Environmental Sciences, Chinese Academy of Sciences, Beijing 100085, China \\ ${ }^{\mathrm{b}}$ University of Chinese Academy of Sciences, Beijing 100039, China
}

\section{H I G H L I G H T S}

- A novel adsorbent contained amino groups and coordinated $\mathrm{Fe}(\mathrm{III})$ was prepared.

- The adsorbent had high adsorption efficiency for both TC and $\mathrm{Cu}(\mathrm{II})$.

- The synergistic effects of TC and $\mathrm{Cu}(\mathrm{II})$ on the adsorption were found.

- TC-Cu(II) complex act as a bridge between adsorbates and adsorbent.

- $\mathrm{Fe}(\mathrm{III})$ and amino groups were complexed with amide of TC and $\mathrm{Cu}(\mathrm{II})$, respectively.

\section{A R T I C L E I N F O}

\section{Article history:}

Received 17 September 2014

Received in revised form 1 July 2015

Accepted 9 July 2015

Available online 25 July 2015

\section{Keywords:}

Adsorption

Cosorption

Functionalized SBA15

Tetracycline

Copper

\section{G R A P H I C A L A B S T R A C T}
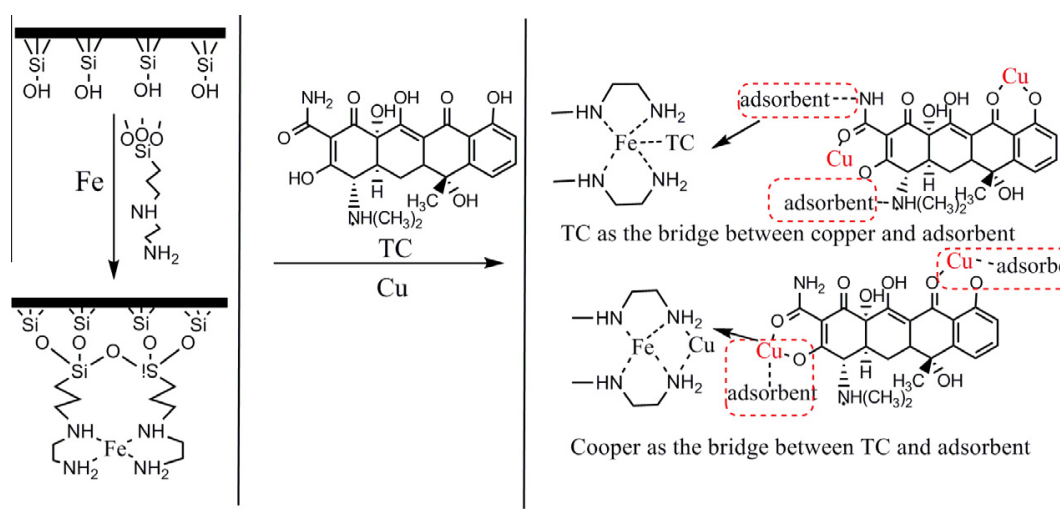

$\mathrm{TC}$ as the bridge between copper and adsorbent

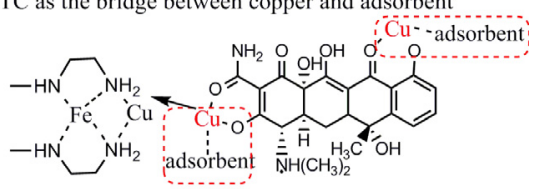

Cooper as the bridge between TC and adsorbent

\section{A B S T R A C T}

Finding effective methods for simultaneous removal of antibiotics and heavy metals has attracted increasing concern since both of them are frequently detected in aquatic environments. In this study, a novel mesoporous silica adsorbent (Fe-N,N-SBA15) contained dual-functional groups was synthesized by first grafting di-amino groups on SBA15, and then coordinating $\mathrm{Fe}(\mathrm{III})$ onto the adsorbent. The adsorbent was then used in the synchronous elimination of tetracycline (TC) and $\mathrm{Cu}(\mathrm{II})$ from water, which was deeply studied by solution $\mathrm{pH}$, kinetics, equilibriums in sole and binary systems. It was found that the adsorbent had high affinity for both $\mathrm{TC}$ and $\mathrm{Cu}(\mathrm{II})$ and synergistic effects on the adsorption were found. The solution $\mathrm{pH}$ remarkably affected the adsorption due to $\mathrm{pH}$-dependent speciation of $\mathrm{TC}, \mathrm{Cu}(\mathrm{II})$, $\mathrm{TC}-\mathrm{Cu}(\mathrm{II})$ complex and the surface properties of the adsorbent. Increasing adsorption amount of TC and $\mathrm{Cu}(\mathrm{II})$ on the adsorbent could be attributed to the formation of complex TC-Cu(II) bridging or the stronger affinity of the adsorbent for the TC-Cu(II) complex than that for TC or $\mathrm{Cu}$ (II) separately. FT-IR and XPS studies revealed that Fe(III) and amino groups on the adsorbent were complexed with the amide of TC and $\mathrm{Cu}(\mathrm{II})$, respectively. The recyclabilities of the adsorbent were also evaluated and the Fe-N,N-SBA15 exhibited good reusability for TC and $\mathrm{Cu}(\mathrm{II})$ removal. This study shows guidelines and offers an innovative, effective method for the synergistic removal of antibiotics and heavy metals from aquatic environments.

(c) 2015 Elsevier Ltd. All rights reserved.

\footnotetext{
* Corresponding author.

E-mail address: hjliu@rcees.ac.cn (H. Liu).
}

\section{Introduction}

In recent years, combined pollution of antibiotics and heavy metal ions has been an increasingly concern in aqueous solution 
due to it reflects the real environment. Antibiotics have been heavily used as a feed additive to treat disease and promote the growth of animals (Polubesova et al., 2006). While antibiotics is poorly absorbed in the digestive tract of animals, and $50-80 \%$ of them are excreted into environment as parent compounds (Sarmah et al., 2006). Heavy metals, which are mostly acute toxic to human and wildlife even in trace level, are widely used as a growth promoter in many animal feeds and in industrial, resulting in high concentrations in some animal wastes and wastewater (Xiong et al., 2010; Yang and Jiang, 2014). The application of animal wastes and wastewater has increased their concentrations in the aquatic environments. Both antibiotics and heavy metals are frequently detected simultaneously in ground water and surface water (Kolpin et al., 2002; Li and Zhang, 2013; Lindsey et al., 2001; Luo et al., 2011; Satapathy et al., 2009). Antibiotics can combine with heavy metals strongly and produce complex species, which makes the behaviors of both compounds more complicated. Furthermore, growing evidence suggests that the toxicity of complex species is generally larger than their individual toxicity (Lian et al., 2013). Consequently, the need for effective elimination methods for antibiotics and heavy metals pollution from aqueous solution has attracted increasing concern.

A variety of treatment methods has been established for the removal of antibiotics and heavy metals from water (Farooq et al., 2002; Le-Minh et al., 2010; Lopez et al., 2003; Zazouli et al., 2009; Zhao et al., 2010). Among these methods, adsorption remains attractive because of its advantages of easy operation, energy savings and high removal capacity. Many adsorbents have been used to adsorb antibiotics or heavy metals from water separately, but fewer were used to remove them together (Figueroa et al., 2004; Ge et al., 2012; Ji et al., 2009; Oh et al., 2007; Sassman and Lee, 2005; Vu et al., 2010; Yang and Jiang, 2014; Hasan et al., 2013). In recent years, the cosorption of antibiotics and heavy metals from water by some adsorbents has been attracting increasing concern due to the realistic demands (Kang et al., 2010; Ling et al., 2013; Wang et al., 2008). Sometimes antagonistic effects on adsorption were found when they coexist. So it is of significance to explore new adsorbents for synergistic removing antibiotics and heavy metals simultaneously from water. Furthermore, as the structure of an adsorbent plays an important role on its properties, investigating the roles of functional groups and interaction processes of simultaneously removal antibiotics and heavy metals can provide more guidelines for operation of water treatment.

Mesoporous silica material has been the focus of explosive interest because of its fascinating characteristics of large surface area, tunable pore structure and well-understood surface chemistry (Bui and Choi, 2009). In order to increase the adsorption capacity of emerging contaminants, surface-modified SBA15 with functional groups has been used as adsorbent for the removal of pollutants from aqueous solution (Bui et al., 2011, 2013; Wu et al., 2013). Amino-functionalized SBA15 has proved to be one of the most useful sorbents for removing heavy metals from water due to its excellent chelating ability (Aguado et al., 2009). Metal grafting SBA15 shows high adsorption capacity in the removal of pharmaceutical drugs for water treatment (Rivera-Jimenez and Hernandez-Maldonado, 2008; Rivera-Jimenez et al., 2010). In connection with the ability of $\mathrm{Fe}(\mathrm{III})$ to form stable complexes with antibiotics (Barbooti et al., 2014), we proposed an adsorbent with dual functionalization of amino groups and $\mathrm{Fe}(\mathrm{III})$ based on SBA15, for synergistic removal of antibiotics and heavy metals, whereas few studies have thoroughly discussed.

The purpose of this work is to preparing a novel adsorbent for removal antibiotics and heavy metals simultaneously. Using SBA15 as support, di-amino groups was first grafted on and then $\mathrm{Fe}(\mathrm{III})$ was complexed with the amino groups, and the adsorbent was designated as Fe-N,N-SBA15. The structure, textural, and morphological properties of the adsorbent were characterized. Due to the high complexation between antibiotics, heavy metals and $\mathrm{Fe}(\mathrm{III})$, amino group, respectively. The adsorption and cosorption of TC and copper on Fe-N,N-SBA15 was systematically investigated because of their great production and consumption in China. Roles of amino and $\mathrm{Fe}(\mathrm{III})$ groups of the sorbent and interaction processes of TC and copper were investigated by studying $\mathrm{pH}$, kinetic and adsorption isotherms in sole and binary systems. In addition, the adsorption mechanisms were elucidated based on the results of Fourier transform infrared spectroscopy (FT-IR) and X-ray photoelectron spectroscopy (XPS).

\section{Experimental section}

\subsection{Reagents and materials}

SBA15 was obtained from Nanjing XFNANO Materials Tech Co., Ltd. N-(2-aminoethyl)-3-aminopropyltriethoxysilane (96\%) was obtained from Alfa. Tetracycline (96\% purity) was obtained from Beijing Jing Ke Hong Da Biotechnology Co., Ltd., and used without further purification. Toluene, acetonitrile, methanol, and isopropanol were HPLC grade and obtained from Fisher Scientific Corp. Other chemicals, including sodium hydroxide, hydrochloric acid, ferric chloride, copper chloride, and oxalic acid were analytical grade. Ultrapure water was used for all experiments.

\subsection{Preparation of $\mathrm{Fe}-\mathrm{N}, \mathrm{N}-\mathrm{SBA} 15$}

The amino-functionalized SBA15 was synthesized in post-synthesis grafting method. For the chemical incorporation of amino-organic moieties, $3 \mathrm{~g}$ of SBA15 was pretreated at $120^{\circ} \mathrm{C}$ for $2 \mathrm{~h}$ in a nitrogen atmosphere to remove water. Then the solid was suspended in toluene and stirred for approximately $1 \mathrm{~h}$. An excess amount of $\mathrm{N}$-(2-aminoethyl)-3-aminopropyltriethoxysilan e was added drop-wise to the slurry and stirred under reflux at about $100^{\circ} \mathrm{C}$ for $24 \mathrm{~h}$. The precipitate was filtered, washed with dry toluene followed by isopropanol and dried overnight, and the product was designated N,N-SBA15. Incorporation of $\mathrm{Fe}(\mathrm{III})$ into $\mathrm{N}, \mathrm{N}-\mathrm{SBA} 15$ was carried out by the reaction of N,N-SBA15 with a $0.1 \mathrm{M}$ isopropanol solution of ferric chloride for $24 \mathrm{~h}$ at $25^{\circ} \mathrm{C}$. The mixture was then filtered, washed with isopropanol and water. Finally the obtained product was air-dried for $12 \mathrm{~h}$, and further dried at $80^{\circ} \mathrm{C}$ overnight named as Fe-N,N-SBA15.

\subsection{Adsorbents characterization}

X-ray powder diffraction (XRD) patterns were obtained using an $X^{\prime}$ pert PRO MPD (PANalytical, Holland). All XRD patterns were collected in the $2 \theta$ range between $0.5^{\circ}$ and $3^{\circ}$ with a scanning rate of $0.01^{\circ} / \mathrm{min}$. The textural properties of the samples were measured via nitrogen adsorption isotherms recorded by a Micromeritics ASAP 2020 HD88 (Mike, USA). The total surface area, pore volume and pore size distribution (PSD) of the samples were calculated with built-in software. PSD were calculated from the desorption branch of the $\mathrm{N}_{2}$ isotherm data using the Barret-Joyner-Halenda (BJH) method. A Tenson 27 FTIR Spectrometer (Bruker, Germany) was used to determine the vibration frequency changes for the functional groups of virgin and adsorbate-loaded Fe-N,N-SBA15. The chemical analyses on the virgin and $\mathrm{TC} / \mathrm{Cu}(\mathrm{II})$ loaded Fe-N,N-SBA15 were conducted by XPS (Kratos AXIS ULTRA, UK). The XPS spectra were obtained by applying a monochromatic Al $\mathrm{K} \alpha(1486.7 \mathrm{eV}) \mathrm{X}$-ray energy source operated at $15 \mathrm{kV}$ and $10 \mathrm{~mA}$. The software packages Vision (PR2.1.3) and CasaXPS (2.3.12Dev7) were used to fit the XPS peaks. 


\subsection{Adsorption experiments}

All experiments were conducted at $25 \pm 1{ }^{\circ} \mathrm{C}$ with an ionic strength of $10 \mathrm{mM} \mathrm{NaCl}$ and all solutions were wrapped with aluminum foil to prevent light-induced decomposition of TC. In this study, all the experiments were performed in triplicate, and the values listed in the figures were calculated by the average. In the kinetic experiments, three sets of $500 \mathrm{~mL}$ solutions with TC concentration of $0.1 \mathrm{mM}, \mathrm{Cu}(\mathrm{II})$ concentration of $0.25 \mathrm{mM}$, and simultaneous TC concentration of $0.1 \mathrm{mM}$ and $\mathrm{Cu}(\mathrm{II})$ concentration of $0.25 \mathrm{mM}$, were prepared respectively. The adsorbent was then added into the solution with a dosage of $1 \mathrm{~g} \mathrm{~L}^{-1}$. The mixed solution was shaken with a speed of $150 \mathrm{rpm}$ in darkness. $\mathrm{HCl}$ and $\mathrm{NaOH}$ solutions with the concentration of $0.1 \mathrm{M}$ were used to adjust the pH to $5.5 \pm 0.1$. The samples were collected at appropriate time intervals, filtered through a $0.45 \mu \mathrm{m}$ membrane filter and the concentrations of the TC and $\mathrm{Cu}$ (II) were analyzed.

The effect of $\mathrm{pH}$ on the simultaneous adsorption of TC and $\mathrm{Cu}(\mathrm{II})$ on Fe-N,N-SBA15 was investigated as follows. First, four sets of $25 \mathrm{~mL}$ solutions were prepared. One set of solutions contained TC concentration of $0.1 \mathrm{mM}$, and the second set of solutions contained $\mathrm{Cu}$ (II) concentration of $0.25 \mathrm{mM}$. The third set of solutions contained TC concentration of $0.1 \mathrm{mM}$ and $\mathrm{Cu}(\mathrm{II})$ concentration of $0.25 \mathrm{mM}$. The fourth set of solutions contained TC concentration of $0.1 \mathrm{mM}$ and $\mathrm{Cu}(\mathrm{II})$ of $0.5 \mathrm{mM}$. Fe-N,N-SBA15 was added into each solution with a dosage of $1 \mathrm{~g} \mathrm{~L}^{-1}$ and the mixed solution was shaken with a speed of $150 \mathrm{rpm}$ for $24 \mathrm{~h}$. The solution $\mathrm{pH}$ was kept at desired values in the range of 3.0-9.0 using $\mathrm{HCl}$ and $\mathrm{NaOH}$ during the adsorption process. Finally, the solutions were filtered and the concentrations of TC and $\mathrm{Cu}(\mathrm{II})$ were analyzed.

Adsorption isotherms of TC with or without $\mathrm{Cu}(\mathrm{II})$ were studied as follows. A series of $25 \mathrm{~mL}$ solutions with TC concentrations of $0-0.25 \mathrm{mM}$, with or without 0.25 or $0.5 \mathrm{mM} \mathrm{Cu}(\mathrm{II})$ were prepared. For the adsorption isotherms of $\mathrm{Cu}(\mathrm{II})$ with or without TC, the initial concentrations of $\mathrm{Cu}$ (II) were $0-2.5 \mathrm{mM}$, and TC concentrations of 0 or $0.1 \mathrm{mM}$. The adsorbent was then added into the solutions with a dosage of $1 \mathrm{~g} \mathrm{~L}^{-1}$ and the solution $\mathrm{pH}$ was kept at $5.5 \pm 0.1$. Other experimental conditions were the same as the $\mathrm{pH}$ effect experiments.

The regeneration of adsorbent was carried out by desorbing $\mathrm{TC} / \mathrm{Cu}$ with $0.1 \mathrm{mM} \mathrm{HCl}$ aqueous solution. After being filtered and washed with ultrapure water, the sorbent were air-dried for $12 \mathrm{~h}$, and further dried at $80^{\circ} \mathrm{C}$ overnight. The amount of residual $\mathrm{TC} / \mathrm{Cu}(\mathrm{II}), \mathrm{Fe}(\mathrm{III})$ and $\mathrm{N}$ atoms on the adsorbent were analyzed.
The TC concentrations were determined by HPLC (Agilent 1260 , USA) at a wavelength of $360 \mathrm{~nm}$. The mobile phase was a mixture of $10 \mathrm{mM}$ aqueous oxalic acid-acetonitrile-methanol (67:22:11,

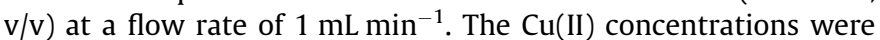
determined by inductively coupled plasma optical emission spectrometer (ICP-OES) (Elan 5000, Perkin Elmer, USA).

\section{Results and discussion}

\subsection{Structure, textural, and morphological properties of $\mathrm{Fe}-\mathrm{N}, \mathrm{N}-\mathrm{SBA} 15$}

The low-angle X-ray powder diffraction data of sorbents are displayed in Fig. 1a. SBA15 exhibited three well-defined diffraction peaks in the range of $0.8-2^{\circ}$, which could be indexed to the (100), (110), (200) planes of the porous structure, suggesting a p6mm symmetry-typical of uniform mesopore structures with hexagonal long-range order (Zhao et al., 1998). Compared with unmodified SBA15, $d_{100}, d_{110}$ and $d_{200}$ were still present for $\mathrm{N}, \mathrm{N}-\mathrm{SBA} 15$, demonstrating that the structure of SBA15 was maintained after the modification. However, the reduction in diffraction intensity revealed some extent of disorder, especially for the $d_{110}$ and $d_{200}$ peaks, which indicated that the amino group had been successfully grafted to SBA15 (Aguado et al., 2009). After coordinated with $\mathrm{Fe}(\mathrm{III})$, the diffraction of the $d_{110}$ and $d_{200}$ peaks nearly disappear, suggesting that the metal modification reduced the scattering power of SBA15 due to the incorporation of metal (Rivera-Jimenez et al., 2010).

SBA15 exhibited the highest surface area, while the loading of amino groups and $\mathrm{Fe}(\mathrm{III})$ resulted in a decrease in the value, following the order $\operatorname{SBA} 15\left(499 \mathrm{~m}^{2} \mathrm{~g}^{-1}\right)>\mathrm{N}, \mathrm{N}-\operatorname{SBA} 15\left(296 \mathrm{~m}^{2} \mathrm{~g}^{-1}\right)>$ Fe-N,N-SBA15 $\left(249 \mathrm{~m}^{2} \mathrm{~g}^{-1}\right)$. The same phenomenon was found with pore volume, decreasing from $0.89 \mathrm{~cm}^{3} \mathrm{~g}^{-1}$ of $\mathrm{SBA}-15$ to $0.49 \mathrm{~cm}^{3} \mathrm{~g}^{-1}$ of Fe-N,N-SBA15 (Table S1). These observations also confirmed the successful loading of functional groups on the surface of SBA15. The FT-IR spectra of the adsorbents (Fig. S1) also confirmed the modification of SBA15 by amino-groups and metals. After modification the isotherms of N,N-SBA15 and Fe-N,N-SBA15 were of type IV with $\mathrm{H} 2$ hysteresis loops, which was typical of SBA15 materials (Fig. 1b). Although the hysteresis shifted to lower relative pressures, a comparison of the PSD curves for adsorbents revealed that the grafting method did not have much influence on the average pore size (Fig. 1b). These observations were in agreement with the low-angle XRD patterns findings, suggesting
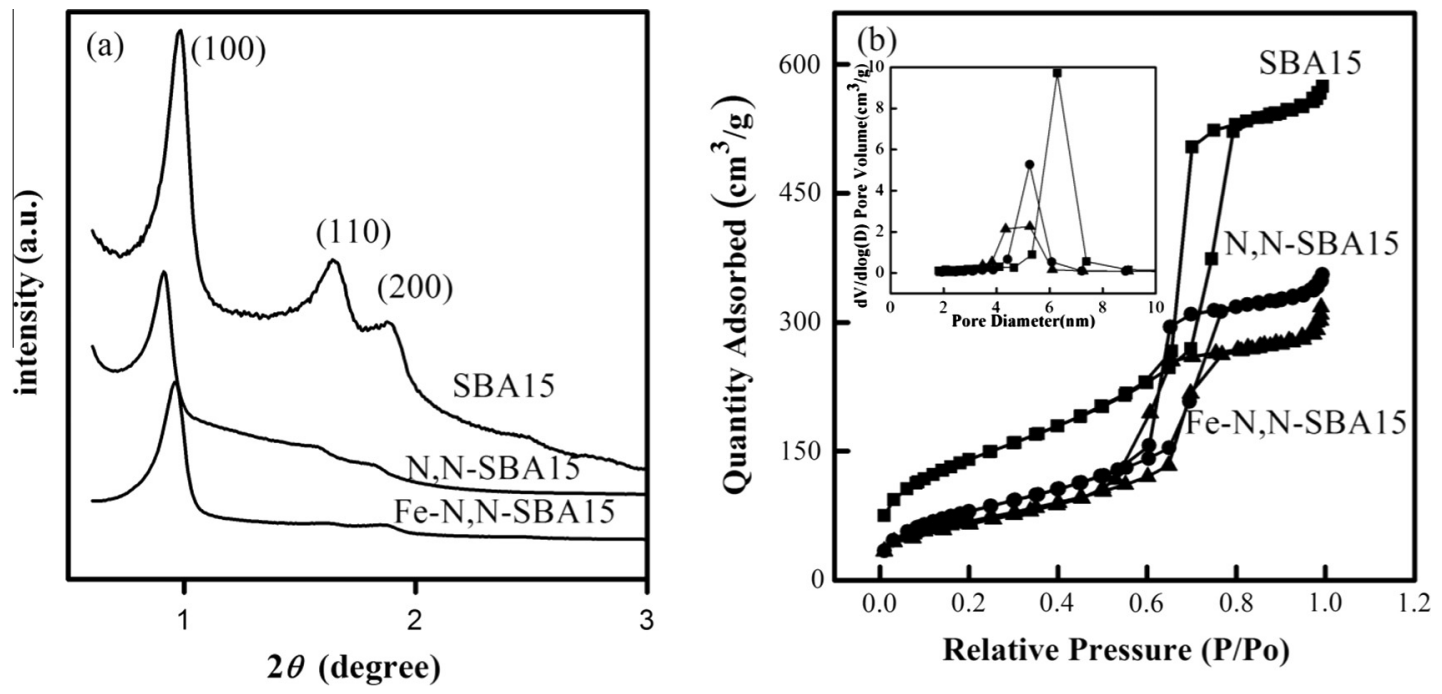

Fig. 1. Characterization of studied samples by: (a) XRD; (b) $\mathrm{N}_{2}$ adsorption/desorption isotherms and inset with PSD curve. 
that the adsorbents preserved the mesoporous structural order after the functionalization of the amino/metal groups.

\subsection{Adsorption kinetics}

The adsorption and cosorption kinetics of $\mathrm{TC}$ and $\mathrm{Cu}(\mathrm{II})$ onto Fe-N,N-SBA15 are shown in Fig. 2. For the sole system, TC or $\mathrm{Cu}$ (II) was adsorbed rapidly in the first $30 \mathrm{~min}$, and followed by a relatively slow process. The rapid adsorption rate could be attributed to the rigid, open-pore structure as well as the large pore size of adsorbent, which increased the internal mass transfer in the adsorption process. Furthermore, the protonated amino group and $\mathrm{Fe}(\mathrm{III})$ inside the pore walls could provide abundant binding sites for $\mathrm{Cu}(\mathrm{II})$ and TC, respectively (Barbooti et al., 2014; Yang and Jiang, 2014). For the binary system, the presence of $\mathrm{Cu}(\mathrm{II})$ increased the adsorption rate of TC and enhanced the amount of absorbed TC to more than twice values in the absence of $\mathrm{Cu}$ (II) (Fig. 2a). As shown in Fig. 2b, the presence of TC also facilitated the adsorption of $\mathrm{Cu}(\mathrm{II})$. TC and $\mathrm{Cu}(\mathrm{II})$ could facilitate the adsorption of one another, which might be attributed to the strong chelating capability of TC and $\mathrm{Cu}(\mathrm{II})$. The $\mathrm{Cu}(\mathrm{II})$ and TC, which adsorbed on different sites of Fe-N,N-SBA15, could chelate the TC and $\mathrm{Cu}(\mathrm{II})$ in the solution by formation of TC-Cu(II) complexes with higher sorption affinity (Ling et al., 2013).

\subsection{Effect of $\mathrm{pH}$ on adsorption and cosorption of TC and $\mathrm{Cu}(\mathrm{II})$}

Fig. 3a shows that solution pH remarkably affected TC adsorption on $\mathrm{Fe}-\mathrm{N}, \mathrm{N}-\mathrm{SBA} 15$, and the presence of $\mathrm{Cu}(\mathrm{II})$ can increases TC adsorption significantly. In the absence or presence of $0.25 \mathrm{mM} \mathrm{Cu}(\mathrm{II})$, the adsorption of TC increases to a maximum and then decreases with increasing solution $\mathrm{pH}$. In the presence of $0.5 \mathrm{mM} \mathrm{Cu}(\mathrm{II})$, the adsorption of TC increases when the solution $\mathrm{pH}$ is increased from 3.1 to 6.0 and then remains unchanged with the solution $\mathrm{pH}$ increased further. As displayed in Fig. 3b, the $\mathrm{Cu}(\mathrm{II})$ adsorption on Fe-N,N-SBA15 with and without TC increases with the solution $\mathrm{pH}$ increases up to 5.5, then it remains unchanged as the solution $\mathrm{pH}$ is further increased to 9.0. It also can be seen
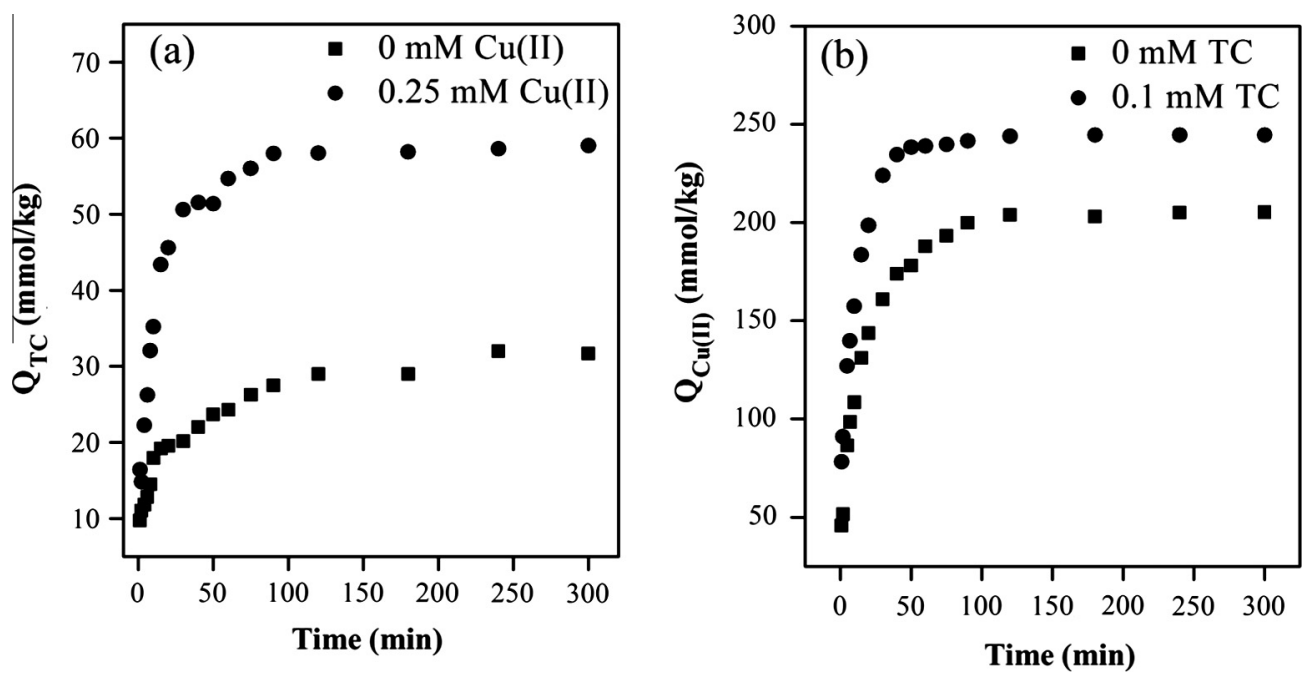

Fig. 2. Adsorption kinetics of TC and $\mathrm{Cu}(\mathrm{II})$ onto Fe-N,N-SBA15. (a) TC adsorption in the absence or presence of $\mathrm{Cu}(\mathrm{II})$. Experimental conditions: $[\mathrm{TC}]_{0}=0.1 \mathrm{mM}$, $[\mathrm{Cu}(\mathrm{II})]_{0}=0$ or $0.25 \mathrm{mM}, m=1 \mathrm{~g} \mathrm{~L}^{-1}, \mathrm{pH}=5.5 \pm 0.1, T=25^{\circ} \mathrm{C}$. (b) $\mathrm{Cu}(\mathrm{II})$ adsorption in the absence or presence of TC. Experimental conditions: $[\mathrm{Cu}(\mathrm{II})]_{0}=0.25 \mathrm{mM},[\mathrm{TC}]_{0}=0$ or $0.1 \mathrm{mM}$, $m=1 \mathrm{~g} \mathrm{~L}^{-1}, \mathrm{pH}=5.5 \pm 0.1, T=25^{\circ} \mathrm{C}$.
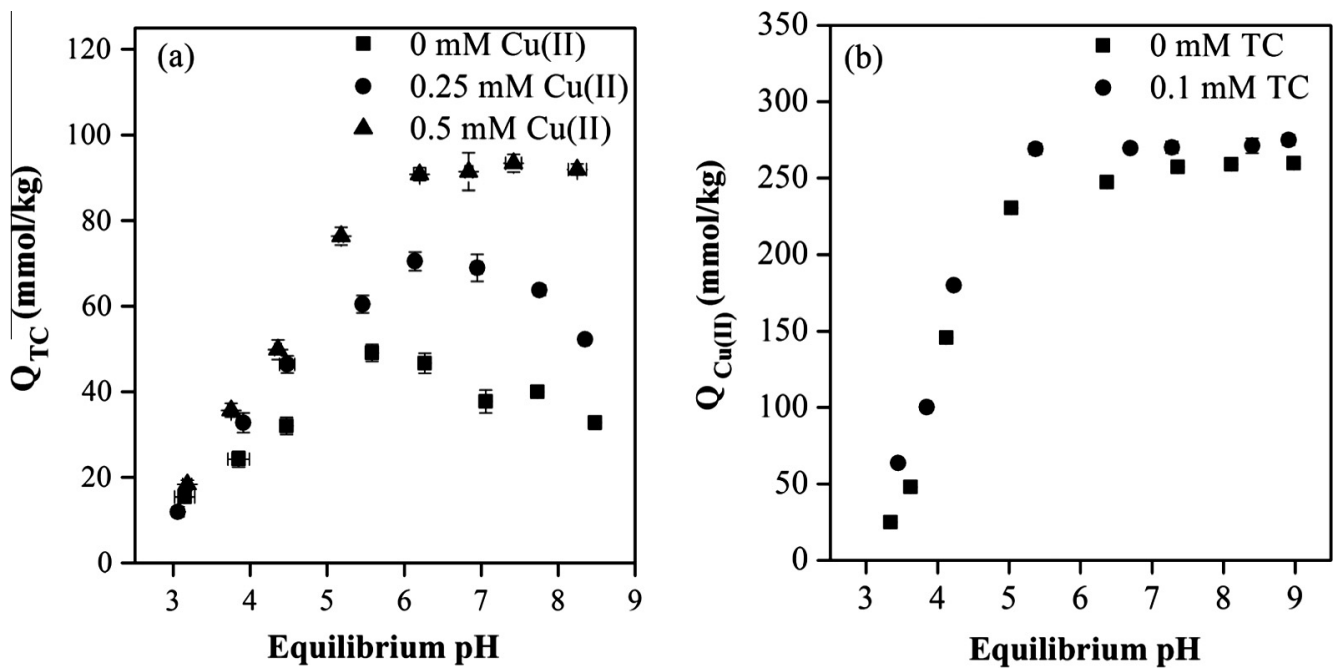

Fig. 3. Effect of $\mathrm{pH}$ on adsorption of $\mathrm{TC}$ and $\mathrm{Cu}(\mathrm{II})$. (a) Effect of $\mathrm{pH}$ on $\mathrm{TC}$ adsorption in the absence or presence of $\mathrm{Cu}(\mathrm{II})$. Experimental conditions: $[\mathrm{TC}]_{0}=0.1 \mathrm{mM},[\mathrm{Cu}(\mathrm{II})]_{0}=0$, 0.25 or $0.5 \mathrm{mM}, m=1 \mathrm{~g} \mathrm{~L}^{-1}, T=25^{\circ} \mathrm{C}$. (b) Effect of $\mathrm{pH}$ on Cu(II) adsorption in the absence or presence of TC. Experimental conditions: $[\mathrm{Cu}(\mathrm{II})]_{0}=0.25 \mathrm{mM},[\mathrm{TC}]_{0}=0$ or $0.1 \mathrm{mM}$, $m=1 \mathrm{~g} \mathrm{~L}^{-1}, T=25^{\circ} \mathrm{C}$. 
that the presence of TC increases the adsorption amount of $\mathrm{Cu}(\mathrm{II})$ on the adsorbent.

The results showed above can be associated with the $\mathrm{pH}$-dependent speciation of TC, $\mathrm{Cu}(\mathrm{II})$, the complex of TC-Cu(II) and the surface properties of the adsorbent. Results of zeta potential measurements of the adsorbent indicated that the surface of Fe-N,N-SBA15 was positively charged over the studied $\mathrm{pH}$ range (Fig. S2). TC (symbolized as $\mathrm{H}_{2} \mathrm{~L}$ ) is an amphoteric molecule and formed a series of species at different $\mathrm{pH}$ levels, the distribution of various species was calculated by MINEQL ${ }^{+}$(Kang et al., 2010). The predominant TC species were $\mathrm{H}_{3} \mathrm{~L}^{+}$at $\mathrm{pH}<3.4, \mathrm{H}_{2} \mathrm{~L}$ at $3.4<\mathrm{pH}<7.6, \mathrm{HL}^{-}$at $7.6<\mathrm{pH}<9.0$, and $\mathrm{L}^{2-}$ at $\mathrm{pH}>9.0$ (Fig. S3). With $\mathrm{pH}$ increasing from 3.0 to 5.5, the percentage of the neutral form $\left(\mathrm{H}_{2} \mathrm{~L}\right)$ increased and the amino group on TC was more easily complexed with $\mathrm{Fe}(\mathrm{III})$ on the adsorbent due to the electrostatic attractions, which increased the amount of adsorption (Lian et al., 2013). With the $\mathrm{pH}$ further increasing, the percentage of anionic form $\left(\mathrm{HL}^{-}, \mathrm{L}^{2-}\right)$ increased, which inhibits the adsorption of TC on Fe-N,N-SBA15 due to the electrostatic repulsion. The adsorbent contains amino groups, which have a strong complexing capability with $\mathrm{Cu}(\mathrm{II})$. With increasing $\mathrm{pH}$, the positive charge of the adsorbent decreases (Fig. S2), due to the increasing electrostatic attraction, the adsorption amount of $\mathrm{Cu}(\mathrm{II})$ is enhanced.

When $\mathrm{TC}$ and $\mathrm{Cu}(\mathrm{II})$ were present in the solution simultaneously, the strong chelating capability between TC and $\mathrm{Cu}(\mathrm{II})$ resulted in complex species. The distribution of $\mathrm{TC}-\mathrm{Cu}(\mathrm{II})$ species was determined by the $\mathrm{MINIQL}^{+}$including $\mathrm{Cu}\left(\mathrm{H}_{2} \mathrm{~L}\right)^{2+}, \mathrm{Cu}(\mathrm{HL})^{+}$, $\mathrm{Cu}(\mathrm{L}), \mathrm{Cu}\left(\mathrm{H}_{4} \mathrm{~L}_{2}\right)^{2+},\left(\mathrm{CuH}_{3} \mathrm{~L}_{2}\right)^{+},\left(\mathrm{CuH}_{2} \mathrm{~L}_{2}\right),\left(\mathrm{CuHL}_{2}\right)^{-}$(Fig. S3) (Kang et al., 2010). The synergistic effect of TC and $\mathrm{Cu}(\mathrm{II})$ adsorption might be ascribed to the strong complex formation between TC and $\mathrm{Cu}(\mathrm{II})$. The $\mathrm{Cu}(\mathrm{II})$ or TC could act as a bridge between the adsorbate and Fe-N,N-SBA15. Furthermore, the complex of TC-Cu(II) may have stronger affinity to the adsorbent than TC and $\mathrm{Cu}(\mathrm{II})$ separately. A similar observation was reported on the adsorption of TC on waste tire powder and montmorillonite (Lian et al., 2013; Wang et al., 2008).

\subsection{Adsorption isotherms}

Adsorption isotherms of TC on Fe-N,N-SBA15 at pH 5.5 with and without $\mathrm{Cu}(\mathrm{II})$ are shown in Fig. 4a. The amount of TC adsorbed on Fe-N,N-SBA15 increased with increasing TC equilibrium concentration. The adsorption amount of TC was significantly enhanced with the increasing concentration of $\mathrm{Cu}(\mathrm{II})$. The same phenomena was reported for the adsorption of TC onto chelating resin and tire powder (Lian et al., 2013; Ling et al., 2013). Lian et al. confirmed that TC and $\mathrm{Cu}(\mathrm{II})$ facilitated the sorption of one another on tire powder through the formation of $\mathrm{TC}-\mathrm{Cu}(\mathrm{II})$ complexes. Ling et al. inferred that resin-Cu(II) bridging to TC was the leading mechanism for the adsorption of TC.

Adsorption isotherms of $\mathrm{Cu}(\mathrm{II})$ on Fe-N,N-SBA15 in the absence and the presence of TC are shown in Fig. 4b. The adsorption amount of $\mathrm{Cu}$ (II) on Fe-N,N-SBA15 increased with the increasing equilibrium concentration of $\mathrm{Cu}(\mathrm{II})$. Due to the mesoporous structure and amino-groups of the adsorbent, Fe-N,N-SBA15 has great affinity for the chelate ability of $\mathrm{Cu}(\mathrm{II})$. The presence of TC increased the adsorption capacity of $\mathrm{Cu}$ (II) onto the adsorbent. This result was not consistent with that reported by Kang et al. but agreed with Wang et al. (Kang et al., 2010; Wang et al., 2008). In the Kang et al. results, the adsorption mechanism was due to the formation of $\mathrm{Cu}$ (II)/TC-organic complexes on the surface of chitosan. TC competed with $\mathrm{Cu}$ (II) for the functional groups on chitosan, leading to less adsorption amount of $\mathrm{Cu}$ (II). In our study, the main functional groups of adsorbent were $\mathrm{Fe}(\mathrm{III})$ and amino groups, due to the complexation-bridging between $\mathrm{Cu}(\mathrm{II})-\mathrm{TC}$ and TC-Fe(III) on the adsorbent, the adsorption capacity of $\mathrm{Cu}(\mathrm{II})$ was enhanced. Furthermore, as mentioned above, the TC-Cu(II) complex may have stronger affinity on Fe-N,N-SBA15 than TC and $\mathrm{Cu}$ (II) separately.

The adsorption data were fitted by Langmuir and Freundlich model isotherm equations, respectively (Ling et al., 2013). The calculated parameters are listed in Table 1. The Langmuir isotherm assumes the adsorbate forms a monolayer around the homogenous surface of the adsorbent and Freundlich model assumes that adsorption takes place on a heterogeneous surface. Compared with the Langmuir model, the Freundlich model fits the adsorption isotherms better $\left(R^{2}=0.92-0.97\right)$, which indicates that the uptake of $\mathrm{TC}$ and $\mathrm{Cu}(\mathrm{II})$ on the sorbent is multilayer adsorption. The results were attributed to adsorption site heterogeneity, with possibilities of $\mathrm{TC}-\mathrm{Fe}(\mathrm{III})$ interaction, $\mathrm{TC}-\mathrm{Cu}(\mathrm{II})$ interaction and $\mathrm{Cu}(\mathrm{II})$-amino interaction. The values of $K_{f}$ and $1 / n$ for all the results suggested the adsorbent was favorable for the removal of TC and $\mathrm{Cu}$ (II) from aqueous solution (Wang et al., 2008).
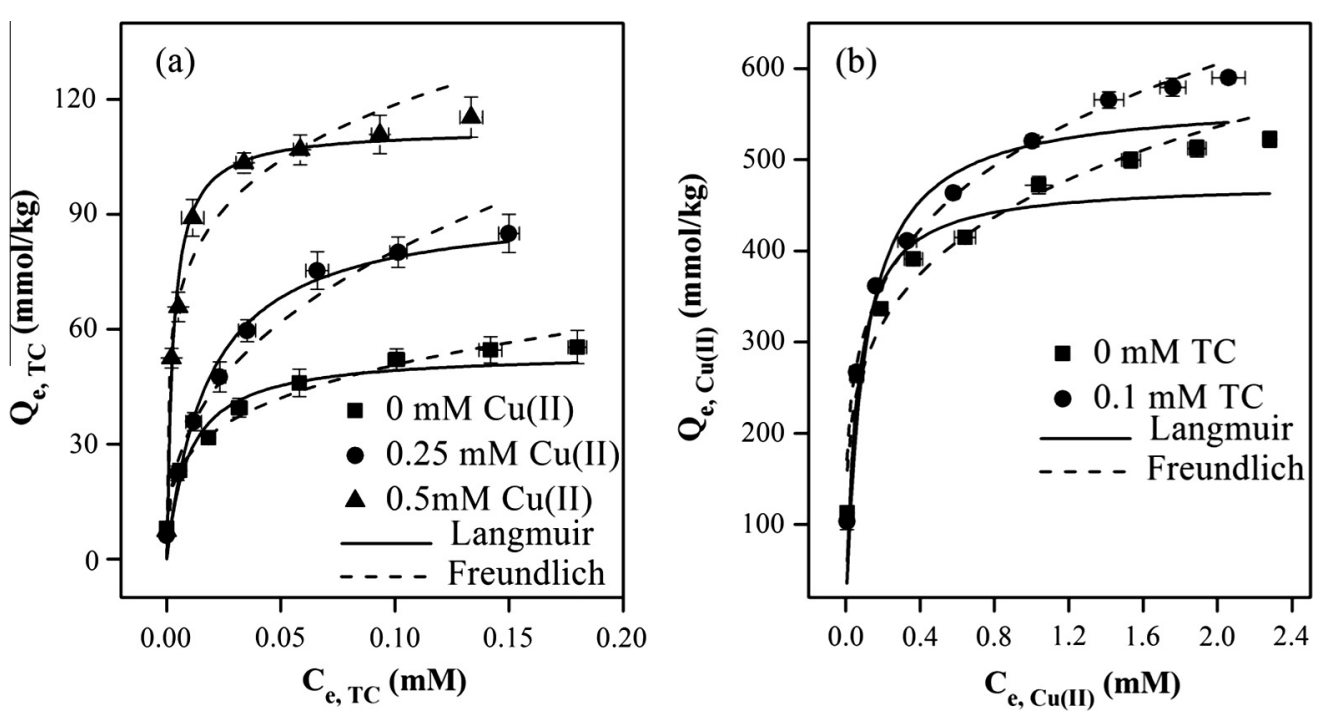

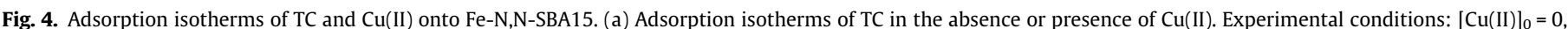

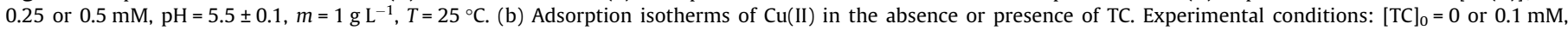
$\mathrm{pH}=5.5 \pm 0.1, m=1 \mathrm{~g} \mathrm{~L}^{-1}, T=25^{\circ} \mathrm{C}$. 
Table 1

Langmuir and Freundlich parameters for the adsorption of $\mathrm{TC}$ and $\mathrm{Cu}(\mathrm{II})$.

\begin{tabular}{|c|c|c|c|c|c|c|c|}
\hline \multicolumn{2}{|c|}{ Initial concentration (mM) } & \multicolumn{3}{|l|}{ Langmuir } & \multicolumn{3}{|l|}{ Freundlich } \\
\hline & & $Q_{\max }\left(\mathrm{mmol} \mathrm{kg}^{-1}\right)$ & $b\left(\mathrm{~L} \mathrm{mmol}^{-1}\right)$ & $R^{2}$ & $K_{f}\left(\mathrm{mmol}^{1-\mathrm{n}} \mathrm{L}^{\mathrm{n}} \mathrm{kg}^{-1}\right)$ & $1 / n$ & $R^{2}$ \\
\hline \multirow[t]{3}{*}{$\mathrm{TC}=0.1$} & $\mathrm{Cu}(\mathrm{II})=0$ & 53.9 & 104.4 & 0.90 & 93.6 & 0.27 & 0.92 \\
\hline & $\mathrm{Cu}(\mathrm{II})=0.25$ & 92.9 & 155.7 & 0.88 & 192.2 & 0.38 & 0.96 \\
\hline & $\mathrm{Cu}(\mathrm{II})=0.5$ & 112.3 & 325.8 & 0.96 & 183.8 & 0.18 & 0.96 \\
\hline \multirow[t]{2}{*}{$\mathrm{Cu}(\mathrm{II})=0.25$} & $\mathrm{TC}=0$ & 475.1 & 16.7 & 0.92 & 459.4 & 0.22 & 0.96 \\
\hline & $\mathrm{TC}=0.1$ & 567.0 & 10.0 & 0.88 & 518.4 & 0.32 & 0.97 \\
\hline
\end{tabular}

The maximum adsorption capacity $\left(Q_{\max }\right)$ calculated by the Langmuir models indicated that the presence of $\mathrm{Cu}(\mathrm{II})$ and TC facilitated the adsorption of each other on the Fe-N,N-SBA15. These results all indicate that $\mathrm{Fe}-\mathrm{N}, \mathrm{N}-\mathrm{SBA} 15$ can remove TC and $\mathrm{Cu}(\mathrm{II})$ simultaneously from aqueous solution.

\subsection{Adsorption mechanism}

FT-IR and XPS analyses are used to investigate the adsorption mechanism of TC and $\mathrm{Cu}(\mathrm{II})$ on Fe-N,N-SBA15. FT-IR spectra of virgin and adsorbate-loaded adsorbents are shown in Fig. 5.

TC is an amphoteric molecule and possesses tricarbonylamide, phenolic diketone, and dimethylamine groups (Fig. 5), and the main characteristic peaks of TC are located in the range of $1200-1700 \mathrm{~cm}^{-1}$. As shown in Fig. $5 \mathrm{~d}$, the peaks at $1523 \mathrm{~cm}^{-1}$ and $1674 \mathrm{~cm}^{-1}$ are attributed to the vibration of $\mathrm{NH}_{2}$ amide and $\mathrm{C}=\mathrm{O}$ amide groups of ring $\mathrm{A}$, respectively. The peaks at $1616 \mathrm{~cm}^{-1}$ and $1456 \mathrm{~cm}^{-1}$ can be assigned to the $\mathrm{C}=0$ stretching of ring $\mathrm{A}$ and the $\mathrm{C}-\mathrm{C}$ stretching vibration, respectively (Parolo et al., 2010, 2008). The appearance of these peaks in the spectrum of TC-loaded adsorbent indicated that TC was adsorbed onto the surface of adsorbent. Compared with the TC spectrum, the peaks of the $\mathrm{NH}_{2}$ amide and $\mathrm{C}=\mathrm{O}$ amide shifted to lower frequencies, implying interaction between the amide group of TC and $\mathrm{Fe}(\mathrm{III})$ on the adsorbent (Fig. 5c). After $\mathrm{Cu}$ (II) adsorption, the bands of $\mathrm{N}-\mathrm{H}$ on the adsorbent shifted slightly, indicating the amino-group plays an important role in the adsorption of $\mathrm{Cu}(\mathrm{II})$ due to the strong chelating capability between $\mathrm{Cu}$ (II) and amino groups on the adsorbent (Fig. $5 b$ ).

To further investigate the interactions between the adsorbent and adsorbate, XPS characterization of adsorbents before and after the adsorption of TC and $\mathrm{Cu}(\mathrm{II})$ were conducted. The wide scan results (Fig. S4) clearly show that the adsorbent is composed of $\mathrm{C}, \mathrm{N}, \mathrm{O}$ and $\mathrm{Si}$ elements. After the $\mathrm{Cu}(\mathrm{II})$ or $\mathrm{TC} / \mathrm{Cu}(\mathrm{II})$ adsorption, the appearance of a small peak around $933 \mathrm{eV}$ indicates the adsorption of $\mathrm{Cu}(\mathrm{II})$ on the Fe-N,N-SBA15.

The high resolution Fe 2p XPS spectra of Fe-N,N-SBA15 before and after adsorption are shown in Fig. 6. The peak positions of Fe $2 \mathrm{p}_{3 / 2}$ and $\mathrm{Fe} 2 \mathrm{p}_{1 / 2}$ have been reported to be around 711 and $724 \mathrm{eV}$, respectively (Grosvenor et al., 2004; Yamashita and Hayes, 2008). After TC loading, the peak of Fe $2 \mathrm{p}_{3 / 2}$ increased from $710.5 \mathrm{eV}$ to $710.9 \mathrm{eV}$, indicating the interaction between $\mathrm{Fe}(\mathrm{III})$ and TC. After $\mathrm{Cu}(\mathrm{II})$ uptake, the peak of $710.5 \mathrm{eV}$ (in virgin adsorbent) shifted to $711.4 \mathrm{eV}(\mathrm{Cu}(\mathrm{II})$ and $\mathrm{TC} / \mathrm{Cu}(\mathrm{II})$-loaded adsorbent). The shift of the binding energy could be attributed to the interaction of $\mathrm{Cu}$ (II) and amino groups. When $\mathrm{Cu}$ (II) was added into the solution, some of the amino groups on Fe-N,N-SBA15 could combine with $\mathrm{Cu}(\mathrm{II})$, as the amino exhibits strong affinity towards $\mathrm{Cu}(\mathrm{II})$, therefore inducing an increased binding energy for Fe(III). For the $\mathrm{TC} / \mathrm{Cu}(\mathrm{II})$-loaded sample, the binding energy of $\mathrm{Fe} 2 \mathrm{p}_{3 / 2}$ increased slightly, suggesting that TC-Cu(II) complex formed and influenced the adsorption of $\mathrm{TC}$ and $\mathrm{Cu}(\mathrm{II})$.

The high resolution $\mathrm{N} 1 \mathrm{~s}$ XPS spectra of the adsorbents before and after adsorption are shown in Fig. 6. The peaks at

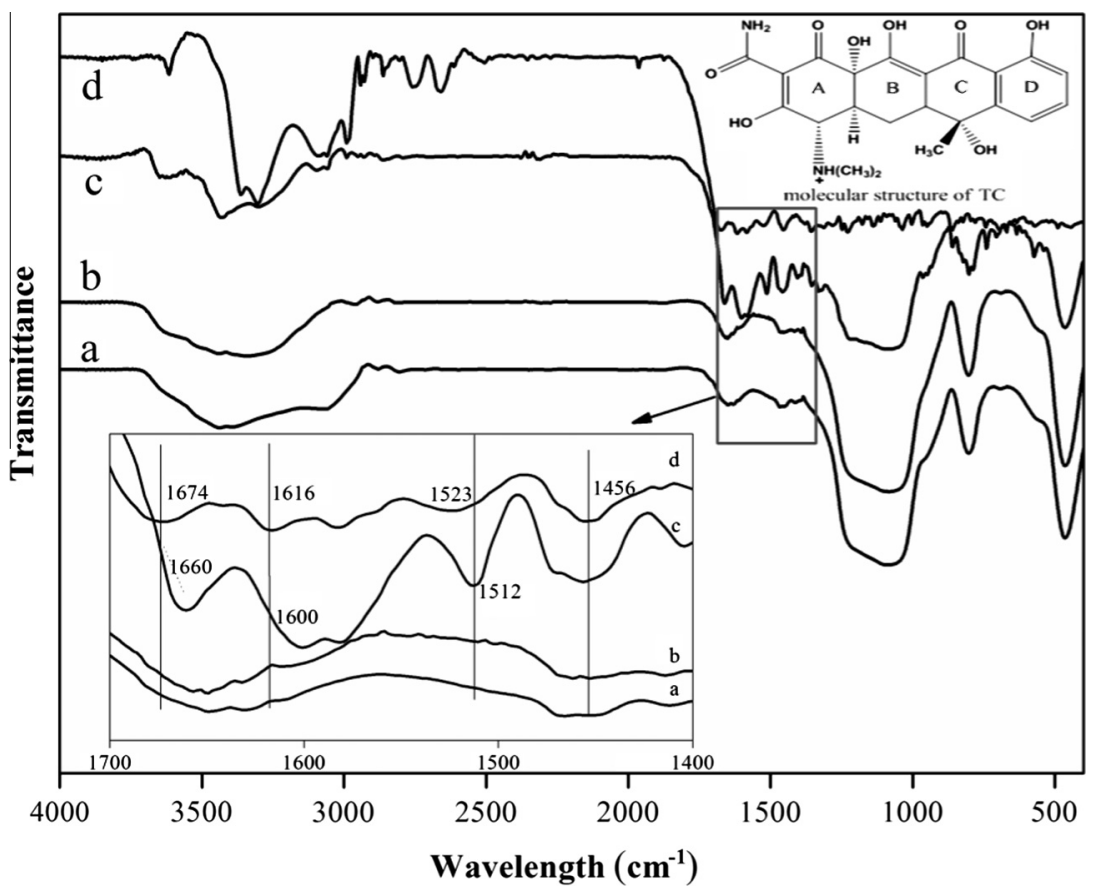

Fig. 5. FT-IR spectra of (a) Fe-N,N-SBA15; (b) Cu(II)-loaded Fe-N,N-SBA15; (c) TC-loaded Fe-N,N-SBA15; (d) TC. 


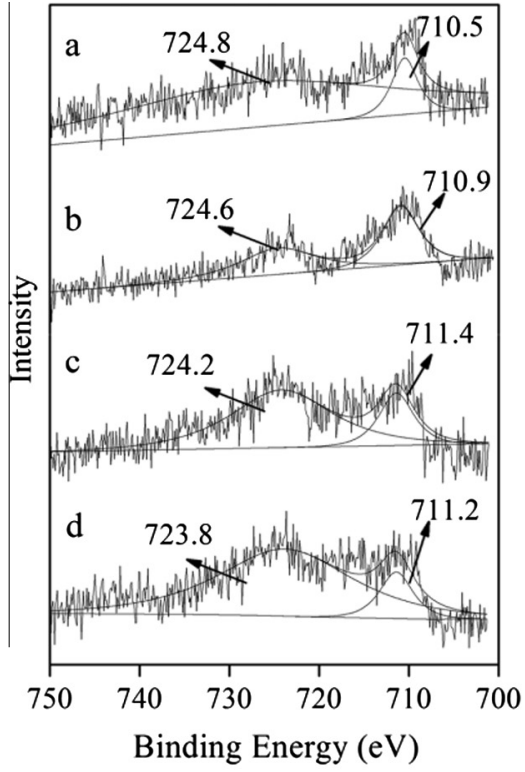

$\mathrm{Fe} 2 \mathrm{p}$

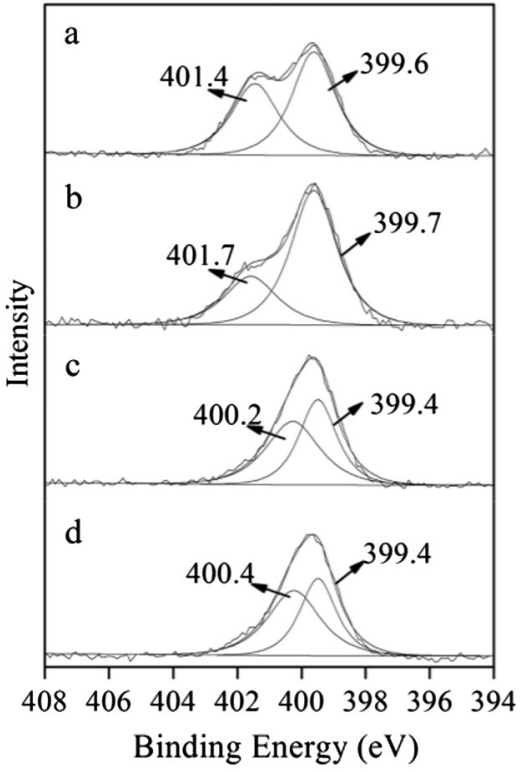

$\mathrm{N} 1 \mathrm{~s}$

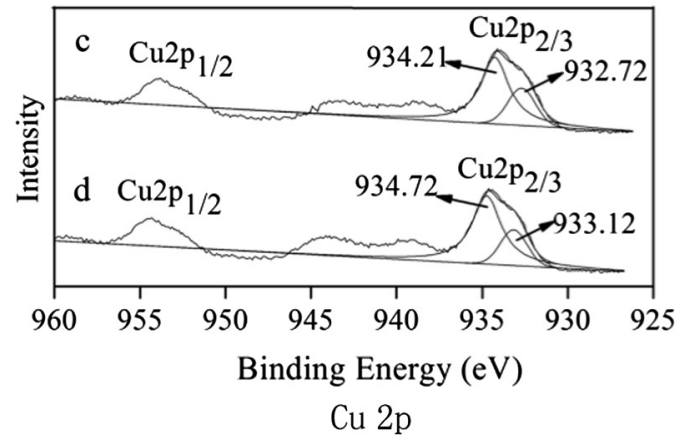

Fig. 6. The XPS spectra of Fe 2p, N 1s, Cu 2p on (a) Fe-N,N-SBA15; (b) TC-loaded Fe-N,N-SBA15; (c) Cu(II)-loaded Fe-N,N-SBA15; (d) TC/Cu(II)-loaded Fe-N,N-SBA15.

399.3 $-399.6 \mathrm{eV}$ can be assigned to $-\mathrm{NH}_{2}$ or $-\mathrm{NH}$, and the peak at 401.4-401.7 eV is assigned to amino perturbed by a positive cation, $\mathrm{NH}_{2}-\mathrm{Fe}(\mathrm{III})$, which was also observed by Chen et al. (2009), Zuo et al. (2012). After TC uptake, only slight shifts of the two peaks were observed which attributed to the interaction between $\mathrm{Fe}(\mathrm{III})$ and amide of $\mathrm{TC}$. When $\mathrm{Cu}(\mathrm{II})$ or $\mathrm{TC} / \mathrm{Cu}(\mathrm{II})$ were added, peaks of $\mathrm{NH}_{2}-\mathrm{Fe}(\mathrm{III})$ nearly disappeared, and new peaks at $400.2 \mathrm{eV}$ appeared, which proved the adsorption interaction between $\mathrm{Cu}$ (II) and amine group (Ling et al., 2013). Due to the strong complexation between $\mathrm{Cu}(\mathrm{II})$ and amino groups of the adsorbent, the $\mathrm{N}$ atom donated a lone pair electrons to form the covalent bond $\mathrm{N}-\mathrm{Cu}(\mathrm{II})$, causing the reduction of electron cloud density and locating at a higher binding energy(Kang et al., 2010; Ling et al., 2013). However, the binding energy of peak of $\mathrm{N}-\mathrm{Cu}(\mathrm{II})$ on the $\mathrm{TC} / \mathrm{Cu}(\mathrm{II})$-loaded sample had a higher energy than that with only $\mathrm{Cu}(\mathrm{II})$ loaded, suggesting that the TC-Cu(II) complex participated in a bridging interaction between TC and the adsorbent.

The high resolution XPS spectra of the $\mathrm{Cu}(\mathrm{II}) 2 \mathrm{p}$ are shown in Fig. 6. The peaks centered at 933 and $953 \mathrm{eV}$ should be assigned to the binding energy of the $\mathrm{Cu}$ (II) $2 \mathrm{p}_{2 / 3}$ and $\mathrm{Cu}(\mathrm{II}) 2 \mathrm{p}_{1 / 2}$ level, respectively (Wu et al., 2013; Zhao et al., 2013). After Cu(II) uptake, the peak at the binding energy of 932.72 and $934.21 \mathrm{eV}$ was assigned to the signals of $\mathrm{Cu}(0)$ and $\mathrm{Cu}(\mathrm{II})$, respectively. The presence of $\mathrm{Cu}(0)$ was probably caused by the reducing effect of the amino group, which could convert $\mathrm{Cu}(\mathrm{II})$ species into $\mathrm{Cu}(0)(\mathrm{Wu}$ et al., 2013). After TC/Cu(II) uptake, the two peaks of $\mathrm{Cu}(\mathrm{II}) 2 \mathrm{p}_{2 / 3}$ shifted to 933.12 and $934.72 \mathrm{eV}$, respectively, directly proving the formation of TC-Cu(II) complex.

\subsection{Recyclability}

The reusability of an adsorbent is important for lowering the cost of the adsorption process. For regeneration, $0.1 \mathrm{mM} \mathrm{HCl}$ aqueous solution was used as the desorption of $\mathrm{TC}$ and $\mathrm{Cu}(\mathrm{II})$ from adsorbent. Almost complete desorption of TC and $\mathrm{Cu}(\mathrm{II})$ was achieved and the amount of the residual TC and $\mathrm{Cu}(\mathrm{II})$ were less than $0.4 \mathrm{mmol} \mathrm{kg}^{-1}$ (Table S2). After the acid treatment, most of the organic functional groups were retained and the degree of the residual $\mathrm{N}$ was $92.5 \%$, while almost all of $\mathrm{Fe}(\mathrm{III})$ leached. We re-introduced $\mathrm{Fe}(\mathrm{III})$ to restore the useful adsorption sites, and the degree of restoration of $\mathrm{Fe}(\mathrm{III})$ was $96 \%$. The recyclability of the adsorbent was investigated by repeating the adsorption/desorption process 5 times. After the 5th adsorption/desorption cycle, the adsorption capacity of TC and $\mathrm{Cu}(\mathrm{II})$ onto the adsorbent was approximately $88.5 \%$ and $94.1 \%$ of the initial adsorption amounts, respectively (Fig. S5). The adsorbent exhibited good reusability due to the large pore size, high ratio of meso-pore volume and abundant useful adsorption sites.

\section{Conclusions}

A novel mesoporous silica adsorbent contained amino groups and coordinated $\mathrm{Fe}(\mathrm{III})$ was prepared by grafting method. The 
adsorbent preserve the mesoporous structural order after the functionalization of the amino/metal groups. The resultant adsorbent could be used in adsorption and cosorption of TC and $\mathrm{Cu}$ (II) from aquatic environment. Owing to dual-functional groups, Fe-N,N-SBA15 had high affinity adsorption for both TC and $\mathrm{Cu}(\mathrm{II})$, and synergistic effects on adsorption were found. Increasing adsorption of TC and $\mathrm{Cu}$ (II) on the adsorbent could be attributed to the formation of complex $\mathrm{TC}-\mathrm{Cu}(\mathrm{II})$ bridging or the stronger affinity of the adsorbent for the TC-Cu(II) complex than that TC or $\mathrm{Cu}$ (II) separately. Results also showed that $\mathrm{Fe}(\mathrm{III})$ and amino groups on the adsorbent were complexed with the amide of TC and $\mathrm{Cu}(\mathrm{II})$, respectively. The results also suggest that Fe-N,N-SBA15 is a reusable efficient adsorbent for TC and $\mathrm{Cu}(\mathrm{II})$ removal. This work provides an effective method for the simultaneous removal of antibiotics and heavy metals from aquatic environments.

\section{Acknowledgements}

This work was supported by the National Science Fund for Distinguished Young Scholars of China (Grant No. 51225805) and the National High Technology Research and Development program (Grants 2012AA062606) of China.

\section{Appendix A. Supplementary material}

Supplementary data associated with this article can be found, in the online version, at http://dx.doi.org/10.1016/j.chemosphere. 2015.07.014.

\section{References}

Aguado, J., Arsuaga, J.M., et al., 2009. Aqueous heavy metals removal by adsorption on amine-functionalized mesoporous silica. J. Hazard. Mater. 163, 213-221.

Barbooti, M.M., Su, H., et al., 2014. Oxytetracycline sorption onto Iraqi montmorillonite. Int. J. Environ. Sci. Technol. 11, 69-76.

Bui, T.X., Choi, H., 2009. Adsorptive removal of selected pharmaceuticals by mesoporous silica SBA-15. J. Hazard. Mater. 168, 602-608.

Bui, T.X., Kang, S.Y., et al., 2011. Organically functionalized mesoporous SBA-15 as sorbents for removal of selected pharmaceuticals from water. J. Hazard. Mater. 193, 156-163.

Bui, T.X., Viet Hung, P., et al., 2013. Adsorption of pharmaceuticals onto trimethylsilylated mesoporous SBA-15. J. Hazard. Mater. 254, 345-353.

Chen, X., Lam, K.F., et al., 2009. Synthesis of highly selective magnetic mesoporous adsorbent. J. Phys. Chem. C 113, 9804-9813.

Farooq, R., Wang, Y., et al., 2002. Effect of ultrasound on the removal of copper from the model solutions for copper electrolysis process. Water Res. 36, 3165-3169.

Figueroa, R.A., Leonard, A., et al., 2004. Modeling tetracycline antibiotic sorption to clays. Environ. Sci. Technol. 38, 476-483.

Ge, F., Li, M.M., et al., 2012. Effective removal of heavy metal ions $\mathrm{Cd}^{2+}, \mathrm{Zn}^{2+}, \mathrm{Pb}^{2+}$, $\mathrm{Cu}^{2+}$ from aqueous solution by polymer-modified magnetic nanoparticles. J. Hazard. Mater. 211, 366-372.

Grosvenor, A.P., Kobe, B.A., et al., 2004. Investigation of multiplet splitting of Fe 2p XPS spectra and bonding in iron compounds. Surf. Interface Anal. 36, 15641574.

Hasan, Z., Choi, E., et al., 2013. Adsorption of naproxen and clofibric acid over a metal-organic framework MIL-101 functionalized with acidic and basic groups. Chem. Eng. J. 219, 537-544.

Ji, L., Chen, W., et al., 2009. Mechanisms for strong adsorption of tetracycline to carbon nanotubes: a comparative study using activated carbon and graphite as adsorbents. Environ. Sci. Technol. 43, 2322-2327.

Kang, J., Liu, H., et al., 2010. Systematic study of synergistic and antagonistic effects on adsorption of tetracycline and copper onto a chitosan. J. Colloid. Interf. Sci. $344,117-125$.

Kolpin, D.W., Furlong, E.T., et al., 2002. Pharmaceuticals, hormones, and other organic wastewater contaminants in US streams, 1999-2000: a national reconnaissance. Environ. Sci. Technol. 36, 1202-1211.
Le-Minh, N., Khan, S.J., et al., 2010. Fate of antibiotics during municipal water recycling treatment processes. Water Res. 44, 4295-4323.

Li, B., Zhang, T., 2013. Different removal behaviours of multiple trace antibiotics in municipal wastewater chlorination. Water Res. 47, 2970-2982.

Lian, F., Song, Z., et al., 2013. Mechanistic understanding of tetracycline sorption on waste tire powder and its chars as affected by $\mathrm{Cu}^{2+}$ and $\mathrm{pH}$. Environ. Pollut. 178 264-270.

Lindsey, M.E., Meyer, M., et al., 2001. Analysis of trace levels of sulfonamide and tetracycline antimicrobials, in groundwater and surface water using solid-phase extraction and liquid chromatography/mass spectrometry. Anal. Chem. 73 4640-4646.

Ling, C., Liu, F.Q., et al., 2013. An integrative technique based on synergistic coremoval and sequential recovery of copper and tetracycline with dualfunctional chelating resin: roles of amine and carboxyl groups. ACS Appl. Mater. Interfaces 5, 11808-11817.

Lopez, F.A., Martin, M.I., et al., 2003. Removal of copper ions from aqueous solutions by a steel-making by-product. Water Res. 37, 3883-3890.

Luo, Y., Xu, L., et al., 2011. Occurrence and transport of tetracycline, sulfonamide, quinolone, and macrolide antibiotics in the Haihe River Basin, China. Environ. Sci. Technol. 45, 1827-1833.

Oh, S., Kang, T., et al., 2007. Preparation of novel ceramic membranes modified by mesoporous silica with 3-aminopropyltriethoxysilane (APTES) and its application to $\mathrm{Cu}^{2+}$ separation in the aqueous phase. J. Membrane. Sci. 301, $118-125$.

Parolo, M.E., Avena, M.J., et al., 2010. Antimicrobial properties of tetracycline and minocycline-montmorillonites. Appl. Clay. Sci. 49, 194-199.

Parolo, M.E., Savini, M.C., et al., 2008. Tetracycline adsorption on montmorillonite: pH and ionic strength effects. Appl. Clay. Sci. 40, 179-186.

Polubesova, T., Zadaka, D., et al., 2006. Water remediation by micelle-clay system: case study for tetracycline and sulfonamide antibiotics. Water Res. 40, 23692374.

Rivera-Jimenez, S.M., Hernandez-Maldonado, A.J., 2008. Nickel(II) grafted MCM-41: a novel sorbent for the removal of Naproxen from water. Micropor. Mesopor. Mater. 116, 246-252.

Rivera-Jimenez, S.M., Mendez-Gonzalez, S., et al., 2010. Metal $\left(\mathrm{M}=\mathrm{Co}^{2+}, \mathrm{Ni}^{2+}\right.$, and $\mathrm{Cu}^{2+}$ ) grafted mesoporous SBA-15: effect of transition metal incorporation and $\mathrm{pH}$ conditions on the adsorption of Naproxen from water. Micropor. Mesopor. Mater. 132, 470-479.

Sarmah, A.K., Meyer, M.T., et al., 2006. A global perspective on the use, sales, exposure pathways, occurrence, fate and effects of veterinary antibiotics (VAs) in the environment. Chemosphere 65, 725-759.

Sassman, S.A., Lee, L.S., 2005. Sorption of three tetracyclines by several soils: assessing the role of $\mathrm{pH}$ and cation exchange. Environ. Sci. Technol. 39, $7452-$ 7459.

Satapathy, D.R., Salve, P.R., et al., 2009. Spatial distribution of metals in ground/surface waters in the Chandrapur district (Central India) and their plausible sources. Environ. Geol. 56, 1323-1352.

Vu, B.K., Snisarenko, O., et al., 2010. Adsorption of tetracycline on La-impregnated MCM-41 materials. Environ. Technol. 31, 233-241.

Wang, Y.J., Jia, D.A., et al., 2008. Adsorption and cosorption of tetracycline and copper(II) on montmorillonite as affected by solution pH. Environ. Sci. Technol. 42, 3254-3259.

Wu, L., Wang, H., et al., 2013. Adsorption of Cu(II)-EDTA chelates on tri-ammoniumfunctionalized mesoporous silica from aqueous solution. Sep. Purif. Technol. $117,118-123$.

Xiong, X., Li, Y., et al., 2010. Copper content in animal manures and potential risk of soil copper pollution with animal manure use in agriculture. Resour. Conserv. Recy. 54 (11), 985-990.

Yamashita, T., Hayes, P., 2008. Analysis of XPS spectra of $\mathrm{Fe}^{2+}$ and $\mathrm{Fe}^{3+}$ ions in oxide materials. Appl. Surf. Sci. 254, 2441-2449.

Yang, G.X., Jiang, H., 2014. Amino modification of biochar for enhanced adsorption of copper ions from synthetic wastewater. Water Res. 48, 396-405.

Zazouli, M.A., Susanto, H., et al., 2009. Influences of solution chemistry and polymeric natural organic matter on the removal of aquatic pharmaceutica residuals by nanofiltration. Water Res. 43, 3270-3280.

Zhao, C., Deng, H., et al., 2010. Photodegradation of oxytetracycline in aqueous by $5 \mathrm{~A}$ and $13 \mathrm{X}$ loaded with $\mathrm{TiO}_{2}$ under UV irradiation. J. Hazard. Mater. 176, 884892.

Zhao, D.Y., Feng, J.L., et al., 1998. Triblock copolymer syntheses of mesoporous silica with periodic 50-300 angstrom pores. Science 279, 548-552.

Zhao, X., Guo, L., et al., 2013. Photoelectrocatalytic oxidation of Cu(II)-EDTA at the $\mathrm{TiO}_{2}$ electrode and simultaneous recovery of $\mathrm{Cu}(\mathrm{II})$ by electrodeposition. Environ. Sci. Technol. 47, 4480-4488.

Zuo, J.C., Tong, S.R., et al., 2012. Fe $\mathrm{F}^{3+}$ and amino functioned mesoporous silica: preparation, structural analysis and arsenic adsorption. J. Hazard. Mater. 235, 336-342. 